\title{
Método de índice de qualidade (QIM): desenvolvimento de um protocolo sensorial para corvina (Micropogonias furnieri)
}

\section{Quality Index Method (QIM): development of a sensorial scheme for whitemouth croaker (Micropogonias furnieri)}

\author{
Marcelo Sardenberg Teixeira, ${ }^{*}$ Alexandre Borges, ${ }^{*}$ Róbson Maia Franco, ${ }^{* *}$ Sérgio Carmona de São Clemente, ${ }^{* *}$ \\ Mônica Queiroz de Freitas**
}

\begin{abstract}
Resumo
Os métodos sensoriais são acurados e amplamente utilizados na avaliação do frescor de peixe. Esta pesquisa descreve o desenvolvimento de um protocolo sensorial para corvina (Micropogonias furnieri) baseado no Método de Índice de Qualidade (MIQ). O protocolo de Índice de Qualidade (IQ) pontuou atributos de aspecto geral, de olhos e de brânquias, além da cor do rim e da musculatura, cujo somatório variou de zero (máximo frescor) a 22 (limite de aceitabilidade). As contagens de bactérias atingiram o limite aceitável no $14^{\circ}$ dia de estocagem a $0^{\circ} \mathrm{C}$. O protocolo criado especificamente para a corvina eviscerada poderá ser empregado nos diversos segmentos como na comercialização, estocagem e processamento, reduzindo perdas econômicas e auxiliando na proteção da saúde do consumidor.
\end{abstract}

Palavras-chave: MIQ, análise sensorial, peixe, corvina.

\begin{abstract}
Sensory methods are the accurate and widely used methods to evaluate fish freshness. This paper describes the development of a sensorial scheme for whitemouth croaker (Micropogonias furnieri) based on Quality Index Method (QIM). The Quality Index protocol (QI) it punctuated attributes of general aspect, of eyes, of gills, besides the kidneys' and musculature's color, which sum varied from zero (maximum freshness) to 22 (acceptability limit). The counting of bacterial reached the accepted limit on the 14th day of storage at $0^{\circ} \mathrm{C}$. The protocol specifically created for the gutted whitemouth croaker stored in ice can be used in several segments as commercialization, storage and processing, reducing economical losses and aiding in the protection of the consumer's health.
\end{abstract}

Keywords: QIM, sensory analysis, fish, croaker.

\section{Introdução}

A corvina (Micropogonias furnieri) é considerada, devido a sua abundância, uma das mais tradicionais e importantes espécies da pesca brasileira, argentina e uruguaia. Possui ampla distribuição geográfica, sendo encontrada principalmente nos oceanos Atlântico e Pacífico, e no mar Mediterrâneo. Por ser uma das espécies mais empregadas na dieta das populações costeiras, torna-se, portanto, imprescindível o conhecimento da sua qualidade (Norbis, 1995). Segundo o Ibama (2009), a corvina é a segunda espécie mais representativa do litoral do estado do Rio de Janeiro, tendo sido capturadas $10.064,6$ toneladas no ano de 2007, e na costa brasileira 44.059,5 toneladas.

A análise sensorial é uma ferramenta importante na avaliação da qualidade sensorial do pescado fresco, sendo largamente empregada pelos serviços de inspeção sanitária. No Brasil, as características do peixe fresco, considerado próprio para consumo, são determinadas por legislação como no Regulamento da Inspeção Industrial e Sanitária de Produtos de Origem Animal (RIISPOA) - art. 442 (Brasil, 1997a), na Portaria № 185 do Ministério da Agricultura (Brasil, 1997b) e por normas como as da Associação Brasileira de Normas Técnicas (ABNT,1993). Todavia, tais critérios não consideram a diversidade entre as diferentes espécies e não originam pontuações de qualidade sensorial que expressem o frescor do pescado.

O Método do Índice de Qualidade (MIQ) consiste na avaliação dos diversos atributos de qualidade, como aparência, textura, olhos, guelras, abdome etc., além do odor do pescado resfriado, e na modificação desses atributos de acordo com o tempo de estocagem. A cada atributo é dado um escore,

* Programa de Pós-graduação em Higiene Veterinária e Processamento Tecnológico de Produtos de Origem Animal. Faculdade de Veterinária. Universidade Federal Fluminense (UFF). Niterói/RJ, Brasil.

** Faculdade de Veterinária - UFF. Departamento de Tecnologia dos Alimentos. Rua Dr. Vital Brazil Filho, 64 - Santa Rosa - Niterói/RJ. CEP: 24230-340. E-mail: mqueiroz@vm.uff.br 
que varia de zero a três ou de zero a dois (de acordo com o seu grau de importância), sendo considerado zero como o melhor e três como o pior escore. O peixe, no momento da captura, tem pontuação zero, ou próxima de zero. Conforme vai se deteriorando, os atributos vão adquirindo pontuações mais elevadas, acumulando pontos de demérito, cujo valor máximo varia de acordo com o protocolo desenvolvido para a espécie estudada (Sveinsdottir et al., 2002). A soma desses escores origina o Índice de Qualidade (IQ), o qual permitirá, além da avaliação da qualidade do pescado em questão, a previsão do prazo de vida comercial da espécie estudada, com a vantagem de ser barato, simples, requerer pouco treinamento em relação aos outros métodos e não destruir a amostra (Sveinsdottir et al., 2003).

O MIQ foi adaptado para muitas espécies de pescado: Spaurus aurata (Huidobro et al., 2001), Salmo salar (Sveinsdottir et al., 2002), Merluccius merluccius (Baixas-Nogueras et al., 2003), Sardina pilchardus (Triqui; Bouchriti, 2003), Octopus vulgaris (Barbosa; Vaz-Pires, 2004), Gadus morhua (Esaiassen et al., 2004; Kent et al., 2004; Bonilla et al., 2007), Litopenaeus vannamei (Oliveira, 2005), Salvelinus alpinus (Cyprian et al., 2008), Oreochromis niloticus (Rodrigues, 2008), Sepia officinalis (Sykes, 2009), entre outras.

Segundo Roitman e Travassos (1987), os grupos de bactérias mesófilos e psicrotróficos são utilizados para se estimar a qualidade higiênico-sanitária, estabelecer conformidade das condições sanitárias do transporte, do armazenamento e do processamento e também estipular o provável prazo comercial do alimento. A atual legislação brasileira não prevê limites para contagem em placas de bactérias heterotróficas aeróbias mesófilas em músculo de peixe fresco. A legislação internacional, para este fim, estabelece o limite máximo aceitável de Unidades Formadoras de Colônia (UFC) em 107/g (FAO, 1997). Segundo Frazier e Westhoff (1988), o número de bactérias do muco e da pele de peixes marinhos varia de 100 UFC a vários milhões por $\mathrm{cm}^{2}$ e as brânquias abrigam de $10^{3}$ a $10^{6} \mathrm{UFC} / \mathrm{g}$. A microbiota encontrada na superfície da pele de peixes vivos ou recém-capturados, segundo Huss (1995), varia entre os valores $10^{2}$ a $10^{7} \mathrm{UFC} / \mathrm{cm}^{2}$. Em experimento realizado com corvinas frescas, Ernst (1981) observou um prazo de vida comercial de 16 dias ao iniciar o processo de conservação ainda a bordo, utilizando água do mar com temperatura entre $0^{\circ}$ e $6^{\circ}$, e após desembarcar, utilizando gelo, com trocas a cada dois dias em ambas as situações.

O objetivo deste estudo foi desenvolver um protocolo de caracterização sensorial, empregando-se o MIQ, específico para corvina (Micropogonias furnieri), eviscerada e armazenada à temperatura de $0^{\circ} \mathrm{C}$, determinando o seu grau de frescor.

\section{Material e métodos}

As corvinas, num total de 190 exemplares com peso médio de $700 \mathrm{~g}$, foram adquiridas no período de abril a julho de 2003 junto a uma Associação Livre de Pescadores localizada no município de Niterói, RJ. Após o desembarque, as corvinas eram acondicionadas e transportadas em recipientes isotérmicos contendo gelo reciclável. No laboratório, os exemplares foram imediatamente eviscerados, lavados em água potável, acondicionados em recipientes com gelo, identificados com o dia da captura e mantidos em refrigerador doméstico por 28 dias. Para a análise sensorial foram empregados 180 exemplares e para as análises bacteriológicas, 10 exemplares.

A análise sensorial teve início com o treinamento da equipe de julgadores, formada por quatro mulheres e três homens com idade variando entre 26 e 49 anos, para a elaboração do protocolo MIQ. Este foi realizado em cinco sessões de treinamento, de uma hora cada, utilizando seis exemplares de corvina para cada tempo de armazenamento $(0,4,7,10$ e 14 dias). As amostras eram retiradas do gelo 30 minutos antes de cada sessão, e apresentadas aos julgadores para que os mesmos, em discussão aberta, levantassem os atributos sensoriais de aparência, odor e textura à palpação das corvinas com diferentes tempos de estocagem. Por consenso, ao final do treinamento a equipe elaborou 0 protocolo do IQ para a corvina eviscerada e armazenada em gelo. O protocolo elaborado pelo MIQ foi posteriormente empregado pela equipe treinada, na avaliação de 30 exemplares, utilizando seis deles para cada tempo de armazenamento. As etapas de desenvolvimento do MIQ para a avaliação do frescor das corvinas foram as mesmas estabelecidas por Sveeinsdottir et al. (2003), em salmão (Salmo salar).

Para as análises bacteriológicas, foram retiradas porções de várias regiões da pele e da musculatura do pescado, obtendo-se um "pool" para cada porção, ambas pesando $10 \mathrm{~g}$ cada. Em seguida, transferiu-se cada porção em condições de esterilidade para o envelope de "Stomacher" (modelo 80 da marca Seward) e foram acrescentados $90 \mathrm{~mL}$ de solução salina peptonada $0,1 \%$, sendo homogeneizado durante 120 segundos, obtendo-se a diluição de $10^{-1}$. A partir dessa solução foram preparadas as demais diluições em condições de esterilidade para as análises bacteriológicas. Nesta etapa, foram empregados 10 exemplares de corvina mantidos sob as mesmas condições de estocagem da análise sensorial. Durante 28 dias as porções foram retiradas sob condições assépticas e em seguida os exemplares retornavam para a estocagem, sendo que as coletas das amostras ocorreram em intervalos de dois a três dias, mais precisamente com 0, 2, 4, 7, 9, 11, 14, 16, 18, $21,23,25$ e 28 dias de estocagem em gelo. As semeaduras foram realizadas em duplicata, para as amostras da pele e da musculatura, tanto para a contagem de bactérias heterotróficas aeróbias mesófilas como para a contagem de bactérias heterotróficas aeróbias psicrotróficas, segundo a metodologia recomendada por Morton (2001) e Cousin et al. (2001), respectivamente.

A partir dos resultados do MIQ, dos sete julgadores, de todos os atributos, em cada tempo de estocagem, obteve-se a média e o desvio-padrão dos IQs. A partir dos valores médios de cada um dos atributos sensoriais, nos diferentes tempos de estocagem, procedeu-se à análise de componentes principais em matriz de covariância. Os resultados obtidos nas contagens de bactérias heterotróficas aeróbias mesófilas e psicrotróficas da musculatura e da pele da corvina foram transformados em valores logaritmos e submetidos à análise de regressão. Todas as análises estatísticas descritas foram realizadas no programa estatístico SAS (SAS Institute, Inc., 1999). 


\section{Resultados e discussão}

A equipe treinada pelo $\mathrm{MIQ}$ desenvolveu o protocolo específico para a avaliação da qualidade sensorial da corvina eviscerada e estocada em gelo. O aspecto geral superficial da pele, a firmeza da carne à palpação e o estágio das alterações pósmortais do músculo, observado pela rigidez do peixe, foram características levantadas pela equipe. As variações de cor, forma, e transparência dos olhos, brânquias, rim e musculatura, como também o odor das brânquias das corvinas, foram registradas durante a estocagem por 14 dias. Seguindo a metodologia descrita na literatura, tais atributos receberam pontuações, que variaram de zero a dois, em que os valores mais elevados acumulavam deméritos. A soma final dessas pontuações originou $0 \mathrm{IQ}$ da espécie em estudo, em que o valor zero, ou próximo a zero, representou o peixe recémcapturado, ou seja, de melhor qualidade sensorial quanto ao frescor (Figura 1).

\begin{tabular}{|c|c|c|c|}
\hline \multicolumn{2}{|l|}{ PARÂMETROS } & \multicolumn{2}{|l|}{ CARACTERÍSTICAS } \\
\hline \multirow{9}{*}{ ASPECTO GERAL } & \multirow{3}{*}{ Aspecto superficial } & Pigmentação viva, cores vivas & 0() \\
\hline & & Perda de brilho, cores mais opacas & 1() \\
\hline & & Sem brilho, cores desvanecidas & 2() \\
\hline & \multirow{3}{*}{ Rigidez } & Tenso (rigor) & 0() \\
\hline & & Flexível & 1() \\
\hline & & Mole & 2() \\
\hline & \multirow{3}{*}{ Firmeza da carne } & Muito rígida e firme & 0() \\
\hline & & Ligeiramente mole & 1() \\
\hline & & Mole & 2() \\
\hline \multirow{9}{*}{ OLHOS } & \multirow{3}{*}{$\begin{array}{l}\text { Transparência } \\
\text { (globo ocular) }\end{array}$} & Límpida & 0() \\
\hline & & Ligeiramente opaca & 1() \\
\hline & & Leitosa, opaca & $2(1)$ \\
\hline & \multirow{3}{*}{ Pupila } & Preta-azulada, bem delineada & $0(1)$ \\
\hline & & Enevoada, perda do delineamento & 1() \\
\hline & & Cinzenta, sem delineamento & 2() \\
\hline & \multirow{3}{*}{ Forma } & Protuberante, convexa & 0() \\
\hline & & Achatada, plana & 1() \\
\hline & & Côncava, afundada & 2() \\
\hline \multirow{9}{*}{ BRÂNQUIAS } & \multirow{3}{*}{ Cor } & Vermelho vivo a púrpura & 0() \\
\hline & & Menos viva, pálida nos bordos & 1() \\
\hline & & Descoradas & 2() \\
\hline & \multirow{3}{*}{ Odor } & Algas & $0(1)$ \\
\hline & & Neutro, algas menos intenso & 1() \\
\hline & & Ligeiramente acre ou rançoso & 2() \\
\hline & \multirow{3}{*}{ Forma } & Integra & 0() \\
\hline & & Ligeiramente disforme & 1() \\
\hline & & Disforme & 2() \\
\hline \multirow{3}{*}{ RIM } & \multirow{3}{*}{ Cor } & Vermelho escuro & 0() \\
\hline & & Vinho & 1() \\
\hline & & Marrom & 2() \\
\hline \multirow{3}{*}{ MUSCULATURA } & \multirow{3}{*}{ Aparência e cor } & Translúcida, rósea & $0(1)$ \\
\hline & & Ligeiramente opaca & 1() \\
\hline & & Escura & 2() \\
\hline
\end{tabular}

Figura 1: Protocolo de avaliação do índice de qualidade desenvolvido para a corvina (M. furnieri) eviscerada e estocada em gelo

As pontuações médias obtidas da equipe previamente treinada, formada por sete julgadores, em seis repetições por julgador, levantados a partir da aplicação do MIQ para a corvina eviscerada e armazenada em gelo estão dispostas na Tabela 1, em que se observam valores de IQ mínimo e máximo de zero e 22 , respectivamente.
Tabela 1: Média e desvio-padrão das pontuações do Índice de Qualidade (IQ), em escala de 0 a 22 corvina (M. furnieri) eviscerada e estocada em gelo

\begin{tabular}{c|c}
\hline Tempo de armazenamento (dias) & Pontuação IQ \\
\hline 0 & $0,29(0,60)$ \\
\hline 04 & $6,82(2,16)$ \\
\hline 07 & $11,36(2,28)$ \\
\hline 10 & $15,46(3,10)$ \\
\hline 14 & $19,39(2,15)$ \\
\hline
\end{tabular}

O atributo de qualidade do aspecto superficial demonstrou uma perda de brilho mais evidenciada a partir do 7으 dia de estocagem; o atributo rigidez apresentou um pequeno declínio entre o 7 ํ e o $10^{\circ}$ dia, provavelmente devido à variação individual entre espécimes. A firmeza da carne mensurada de acordo com Martinsdóttir (1997), pela pressão de um dedo sobre a musculatura e observando-se o seu retorno à forma original, demonstrou inicialmente o escore zero, devido ao rigor mortis, evoluindo conforme o processo de autólise normal, concordando com os resultados encontrados por Gill (1995) e Nielsen (1995).

Avaliando as características dos olhos, observaram-se três atributos: transparência do globo ocular, pupila e forma dos olhos. O globo ocular apresentouse límpido até aproximadamente o 7음 dia de estocagem, quando começou a tornar-se turvo; a pupila se comportou de forma bastante semelhante, começando a turvar-se e a perder seu delineamento de uma forma mais evidente entre o $7 \circ$ e o $10^{\circ}$ dia de estocagem. A forma dos olhos começou a se alterar no $4^{\circ}$ dia de estocagem, permanecendo inalterada até o 7으 dia, quando voltou a evoluir. A evolução dos atributos dos olhos ocorreu de forma muito semeIhante no salmão do Atlântico (Salmo salar), segundo trabalho realizado por Sveinsdottir et al. (2002), e na dourada (Sparus aurata), conforme afirma Alasalvar et al. (2001).

O parâmetro brânquias também foi avaliado por três atributos: cor, odor e forma. A cor, inicialmente vermelho vivo, empalideceu a partir das bordas dos filamentos branquiais de maneira constante até o $10^{\circ}$ dia de estocagem, tornando-se, então, descoradas; tal resultado difere dos encontrados por Sveinsdottir et al. (2002), em S. salar, em que a cor das brânquias, apesar da evolução igualmente constante, atingiu o mínimo de frescor cinco dias antes do término do prazo de vida comercial. Já Alasalvar et al. (2001) não consideraram o parâmetro cor das brânquias como bons indicadores de frescor para a dourada ( $S$. aurata), uma vez que nessa espécie tal atributo não evoluiu de maneira constante. Convém ressaltar que a 
coloração inicial das brânquias na corvina, vermelho vivo, foi a mesma observada na truta arco-íris (Onchorynchus mykiss), segundo Chytiri et al. (2004), que concorda com o fato de que tal parâmetro pode ser importante para a avaliação do frescor; por outro lado, Sparus aurata apresen-tou inicialmente uma coloração vermelho escuro das suas brânquias, segundo Alasalvar et al. (2001). Talvez essa diferença na coloração inicial possa ser determinante na evolução do atributo, tornando-o ou não importante na avaliação do frescor. $\mathrm{O}$ atributo odor das brânquias aumentou de forma regular até o último dia de análise, passando de odor brando de algas marinhas para ligeiramente acre ou rançoso, e a forma, por sua vez, teve uma alteração mais notada entre o $4^{\circ}$ e o $10^{\circ}$ dia de armazenamento. O odor acre e rançoso, segundo Olafsdóttir et al. (1997), provavelmente advém das cadeias curtas de ácidos, álcoois, aminas e componentes sulfurosos provenientes da atividade microbiana.

Com relação à cor dos rins, vísceras que se encontram geralmente aderidas à espinha dorsal, a mudança foi bem evidente até o 7ํ dia; a partir daí, a evolução se tornou menos abrupta, porém constante, passando de vermelho escuro ao tom marrom.

O último atributo analisado, aparência e cor da musculatura, apresentou uma evolução semelhante ao atributo odor das brânquias, evoluindo de forma regular até o 14ํ dia de armazenamento, passando de translúcida e rósea para opaca e escura. Esses resultados estão de acordo com os encontrados em anchovas do Mediterrâneo (Engraulis encrasicholus) avaliadas por Pons-Sánchez-Cascado et al. (2005). Porém, discordam dos resultados obtidos por Sveinsdottir et al. (2002), onde a evolução em S. salar foi irregular.

$\mathrm{Na}$ análise de componente principal, observou-se que somente o primeiro componente principal explicou $96 \%$ da variação ocorrida entre as amostras, agrupando-as em dois grupos de acordo com as similaridades entre si. O primeiro grupo composto pelas corvinas com zero e quatro dias de estocagem, e o segundo com sete, dez e 14 dias de estocagem. A análise revelou que os atributos aspecto superficial e odor das brânquias se destacaram dos demais, seguidos pelos atributos transparência do globo ocular e pupila, indicando que os mesmos foram importantes indicadores de frescor das corvinas estudadas, e ainda que, até o quarto dia, as mesmas se apresentaram sensorialmente igual ao espécime recém-capturado, com pontuação de IQ de zero a oito. Tais resultados concordam com Borges et al. (2007) que analisaram valores de bases voláteis totais e de $\mathrm{pH}$ do músculo, além de empregarem a análise descritiva quantitativa para avaliação sensorial da carne cozida de corvina estocada em gelo.

As equações de regressão, em modelo linear, das contagens bacterianas de músculo e pele, assim como seus respectivos valores de coeficientes de determinação e níveis de probabilidade, estão dispostos na Tabela 3. São observados que as variações das contagens de BHAM e BHAP, em função do tempo de estocagem a $0^{\circ} \mathrm{C}$, puderam ser explicadas em 96 a $89 \%$ nos modelos propostos. Tais valores e o nível de significância indicam que a evolução de tais parâmetros ocorreu de forma linear.
Tabela 2: Modelos de equação de regressão de contagens (Log UFC/g) de Bactérias Heterotróficas Aeróbias Mesófilas (BHAM) e Psicrotróficas (BHAP) em corvina eviscerada, em função do dia de estocagem $(\mathrm{X})$ a $0^{\circ} \mathrm{C}$, e seus e respectivos valores de coeficiente de determinação $(R 2)$ e níveis de probabilidade

\begin{tabular}{c|c|c|c}
\hline Contagem bacteriana & Equação & $\mathrm{R}^{2}$ & Prob. $>\mathrm{F}$ \\
\hline BHAM Músculo & $1,631+0,855 . \mathrm{X}$ & 0,92 & 0,0001 \\
\hline BHAP Músculo & $0,735+0,643 . \mathrm{X}$ & 0,96 & 0,0001 \\
\hline BHAM Pele & $3,277+0,767 . \mathrm{X}$ & 0,91 & 0,0001 \\
\hline BHAP Pele & $2,404+0,562 . \mathrm{X}$ & 0,89 & 0,0002 \\
\hline
\end{tabular}

As corvinas recém-capturadas apresentaram, no dia zero, nas contagens de bactérias heterotróficas aeróbias mesófilas da musculatura e da pele, respectivamente os valores de $9,5 \times 10^{3} \mathrm{UFC} / \mathrm{g}$ e $1,0 \times 10^{5} \mathrm{UFC} / \mathrm{g}$. A contagem de bactérias heterotróficas aeróbias psicrotróficas da musculatura e da pele apresentaram, no dia zero, valores iguais de $1,0 \times 10^{2} \mathrm{UFC} / \mathrm{g}$. Observa-se que a musculatura e a pele das corvinas recém-capturadas apresentaram contagens de bactérias heterotróficas aeróbias mesófilas na faixa de $10^{2}$ a $10^{7}$ UFC/g citado por Huss (1995), como sendo indicadora de boas condições de manipulação e estocagem inicial desse pescado, ficando também demonstrado que o ambiente marinho onde as mesmas foram capturadas apresentava baixo nível de poluição. Esse aspecto foi observado por Eiroa (1980), ao relatar que os peixes capturados próximo à costa podem apresentar a microbiota aumentada, em relação aos peixes capturados em águas profundas.

O crescimento das bactérias heterotróficas aeróbias mesófilas na musculatura e na pele da corvina aumentou proporcionalmente, chegando ao 28 dia, respectivamente, com valores de $3,0 \times 10^{15} \mathrm{UFC} / \mathrm{g}$ e $4,0 \times 10^{15} \mathrm{UFC} / \mathrm{g}$. Em relação ao crescimento bacteriano da musculatura e da pele das psicrotróficas, chegaram no 28 dia, respectivamente, com valores de 4,2 X $10^{9} \mathrm{UFC} / \mathrm{g}$ e $9,8 \times 10^{10} \mathrm{UFC} / \mathrm{g}$.

O limite bacteriano estipulado pela Food Agriculture Organization (FAO, 1997) de $10^{7} \mathrm{UFC} / \mathrm{g}$, o qual não provoca danos à saúde humana, foi atingido no músculo e na pele para as bactérias heterotróficas aeróbias mesófilas no $14{ }^{\circ}$ dia, com valores de 1,2 X 107 UFC/g para músculo e 5,6 X107 UFC/g para pele. No mesmo dia, as contagens na musculatura e na pele das bactérias heterotróficas aeróbias psicrotróficas foram, respectivamente, de $1,1 \times 10^{5} \mathrm{UFC} / \mathrm{g}$ e $2,2 \times 10^{6} \mathrm{UFC} / \mathrm{g}$. Tais resultados discordam das pesquisas sobre corvinas (Micropogonias furnieri) e trutas (Cynoscion regalis) evisceradas e descabeçadas realizadas por Townley e Lanier (1981), que utilizando os padrões de qualidade do peixe fresco estipulado pela FDA para bactérias heterotróficas aeróbias mesófilas e psicrotróficas, os limites bacteriológicos para o consumo humano foi atingido em dez dias de armazenagem em gelo.

Os resultados bacteriológicos obtidos na presente pesquisa estão em discordância com aqueles descritos por Montagner 
et al. (2004) para a Micropogonias furnieri eviscerada e estocada a $4^{\circ} \mathrm{C}$, em que as contagens foram altas num curto período de tempo, tendo o prazo comercial reduzido, provavelmente em decorrência da temperatura de estocagem.

No estudo em peixes marinhos inteiros, realizado por Taliadourou et al. (2003), as contagens de mesófilos no músculo de peixes recém-capturados foram em média de 3,5 log (UFC/g) e no 9o dia de estocagem foi de 5,5 log (UFC/ g), superiores em relação aos encontrados no presente trabalho, podendo ser explicado pelo fato de os autores terem trabalhado com peixes não eviscerados. Jay (1992) recomenda a evisceração do peixe como uma forma de descontaminação e o seu armazenamento à temperatura de $0^{\circ} \mathrm{C}$, para que haja um retardo nas alterações enzimáticas e bacterianas, proporcionando um aumento do prazo comercial.

\section{Referências}

ABNT. Associação Brasileira de Normas Técnicas. Normas ABNT Definições das etapas básicas dos fluxos de operações em estabelecimentos produtores/fornecedores de alimentos. NBR 12806/93. 1993.

ALASALVAR, C.; TAYLOR, K.D.A.; OKSUZ, A.; et al. Freshness assessment of cultured sea bream (Sparus aurata) by chemical, physical and sensory methods. Food Chemistry, v. 72, p. 33-40, 2001.

BAIXAS-NOGUERAS, S. et al. Development of quality index method to evaluate freshness in Mediterranean hake (Merluccius merluccius). Journal of Food Science, v. 68, n. 3, p. 1067-1071, 2003.

BARBOSA, A.; VAZ-PIRES, P. Quality index method (QIM): development of a sensorial scheme for common octopus (Octopus vulgaris). Food Control, v. 15, p. 161-168, 2004.

BONILLA, A. C.; SVEINSDOTTIR, K.; MARTINSDOTTIR, E. Development of Quality Index (QIM) scheme for fresh cod (Gadus morhua) fillets and application in shelf life study. Food Control, v. 18, p. 352-358, 2007.

BORGES, Alexandre et al. Qualidade da corvina (Micropogonias furnieri) eviscerada em diferentes períodos de estocagem a $0^{\circ} \mathrm{C}$. Ciência Rural, Santa Maria, v. 37, n. 1, fev. 2007. Disponível em $<$ http://www.scielo.br.

BRASIL. Ministério da Agricultura e do Abastecimento. Secretaria Nacional de Defesa Agropecuária. Lei n³0691 de 29/03/52. Regulamento da Inspeção Industrial e Sanitária de Produtos de Origem Animal. Brasília, DF, 1997a.

BRASIL. Ministério da Agricultura e do Abastecimento. Secretaria Nacional de Defesa Agropecuária. Portaria no 185 de 13/05/97. Regulamento Técnico de Identidade e Qualidade de Peixe Fresco (Inteiro e Eviscerado). Brasília, DF, 1997b.

CHYTIRI, S.; CHOULIARA, I.; SAVVAIDIS, I.N. et al. Microbiological, chemical and sensory assessment of iced whole and filleted aquacultured rainbow trout. Food Microbiology, v. 21, p. 157-165, 2004.

COUSIN, M. A.; JAY, J. M.; VASAVADA, P. C. Psychrotrophic microorganisms. In: DOWENS, F. P.; ITO, K. Compendium of Methods for the Microbiological Examination of foods. 4. ed. American Public Health Association (APHA) Washington, 2001. 676 p. Cap 13, p. 159164.

CYPRIAN, O. O. et al. Application of Quality Index Method (QIM) scheme and effects of short-time temperature abuse in shelf life study of fresh water arctic char (Salvelinus alpinus). Journal of Aquatic Food Product Technology. v. 17, n. 3, p. 303-321, 2008.

\section{Conclusões}

No Método do Índice de Qualidade (MIQ), as pontuações para o Índice de Qualidade (IQ) para corvinas evisceradas variaram de zero (máximo frescor) a 22 (limite de aceitabilidade). O protocolo IQ pontuou um total de 11 atributos, destacandose como indicadores de frescor o aspecto superficial, como cor e brilho, e o odor das brânquias. Sugerem-se para o intervalo de zero a 4 dias de estocagem, um IQ entre zero e 8, para o dia 7 de estocagem um IQ entre 9 e 13, e para o intervalo de 10 a 14 dias um IQ entre 13 e 22. A corvina (Micropogonias furnieri) eviscerada e estocada à temperatura de $0^{\circ} \mathrm{C}$ pode ser consumida com pouco risco para a saúde do consumidor até o 14ํ dia, uma vez que o número de bactérias heterotróficas aeróbias mesófilas e psicrotróficas na musculatura se mantiveram dentro do limite aceitável para o consumo humano.

EIROA, M. N. U. Aspecto microbiológicos relacionados à conservação e ao consumo de pescado. Boletim da Sociedade Brasileira Ciência e Tecnologia de Alimentos, Campinas, v. 54, p. 9-37, 1980.

ERNST, R. C. Refrigeration Science and Technology. Charleston: NOAA, Nat. Marine Fisheries Service., 1981, 352 p.

ESAIASSEN, M. et al. Effects of catching methods on quality changes during storage of cod (Gadus morhua). Lebensm. Wiss. U. Thechnol., v. 37, p. 643-648, 2004.

FOOD AND AGRICULTURE ORGANIZATION-FAO. Aseguramiento de la calidad de los productos pesqueros: Documento Técnico de pesca 334. Roma, 1997. 174 p. Disponível em: www.fao.org. Acesso em: 14 setembro 2008.

FRAZIER, W. C.; WESTHOFF, D. C. Food microbiology. 4. ed. New York: Mc Graw-Hill, 1988. 681 p.

GILL, T. Autolytic changes. In: Quality and quality changes in fresh fish. Rome: FAO. Documento técnico da FAO. n. 348. p. 39-51, 1995. HUIDOBRO, A.; PASTOR TEJADA, M. Quality index method developed for raw gilthead seabream (Spaurus aurata). Journal of food Science, v. 67, n. 7, p. 1202-1205, 2001.

HUSS, H. H. Quality and quality changes in fresh fish: FAO fisheries technical paper 348. Roma: Food and Agriculture Organization of the United Nations, 1995. $193 \mathrm{p}$.

IBAMA, Instituto Brasileiro do Meio Ambiente e dos Recursos Naturais e Renováveis. IBAMA em números, 2007. Disponível em: www.ibama.gov.br. Acesso em: maio 2009.

JAY, J. M. Modern food microbiology. 4. ed. New York: AVI, 1992. 642 p. KENT, M. et al. A new multivariate approach to the problem of fish quality estimation. Food Chemistry, v. 87, p. 531-535, 2004.

MARTINSDÓTTIR, E. Sensory evaluation in research of fish freshness. Proceedings of the Final Meeting of the Concerted Action "Evaluation of Fish Freshness" AIR3CT94 2283. Nantes ,1997. International Institute of Refrigeration p. 306-312.

MONTAGNER, S. T.; SCHERER, R.; LOBATO. L. P. et al. Effect of direct electric current on microbiological quality of white croaker fish (Micropogonias furnieri). Food Microbiology. London: Elsevier Ltd., 2004. Disponível em: www.elsevier.nl/locate/ jnlabr/yfmic. Acesso em: 15 nov. 2004.

MORTON, R. D. Aerobic Plate Count. In: DOWENS, F. P.; ITO, K. Compendium of Methods for the Microbiological Examination of foods. 4. ed. American Public Health Association (APHA) Washington, 2001. 676 p. Cap 7, p. 63- 67.

NORBIS, W. Influence of wind, behaviour and characteristics of the croaker (Micropogonias furnieri) artisanal fishery in the Rio de la Plata (Uruguay). Fisheries Research, n. 22, p. 43-58, 1995. 
OLIVEIRA, V. M. Estudo da qualidade do camarão branco do Pacífico (Litopenaeus vannamei). Niterói, 2005. 91 f. Tese (Doutorado em Higiene Veterinária e Processamento Tecnológico de POA), Universidade Federal Fluminense, Niterói, 2005.

OLAFSDÓTTIR, G.; MARTINSDÓTTIR, E.; OEHLENSCHLAGER, P. etal. Methods to determine the freshness of fish in research and industry. Proceedings of the Final Meeting of the Concerted Action "Evaluation of Fish Freshness". Nantes: International Institute of Refrigeration, 1997, p. 287-296, 396 p.

PONS-SÁNCHEZ-CASCADO, S.; VIDAL-CAROU, M.C.; NUNES, M.L. et al. Sensory analysis to assess the freshness of Mediterranean anchovies (Engraulis encrasicholus) stored in ice. Food Control, 2005. Artigo In Press.

RODRIGUES, T.P. Estudo de critérios para a avaliação da qualidade da tilápia do Nilo (Oreochromis niloticus) cultivada, eviscerada e estocada em gelo. Niterói, 2008. 116 f. Tese (Doutorado em Higiene Veterinária e Processamento Tecnológico de POA), Universidade Federal Fluminense, Niterói, 2008.

ROITMAN, I.; TRAVASSOS, L. Tratado de Microbiologia. São Paulo: Loyola, 1987. 445 p.

STATISTICAL ANALYSES SYSTEMS. SAS ${ }^{R}$ User's guide. Cary:SAS Institute Inc. 1999, 959 p.
SVEINSDOTTIR, K.; MARTINSDÓTTIR, E.;HYLDIG, G.; etal. Application of quality index method (QIM) scheme in shelf-life study of farmed Atlantic Salmon (Salmo salar). Journal of food Science, v. 67, n. 4, 2002.

SVEINSDOTTIR, K.; HYLDIG, G.; MARTINSDÓTTIR, E. Quality Index Method (QIM) scheme developed for farmed Atlantic salmon (Salmo salar). Food Quality and Preference, v.14, p. 237-245, 2003.

SYKES, A.V. Assessment of European cuttlefish (Sepia officinalis, L.) nutritional value and freshness under ice storage using a developed Quality Index Method (QIM) and biochemical methods. Food Science and Technology. v. 42, n. 1, p. 424-432, 2009.

TALIADOUROU, D.; PAPADOPOULOS, V.; DOMVRIDOU, E. et al. Microbiological, chemical and sensory changes of whole and filleted Mediterranean aquacultured sea bass (Dicentrarchus labrax) stored in ice. Journal of the Science of Food and Agriculture, v. 83, n. 13, p. 1373-1379, 2003.

TRIQUI, R.; BOUCHRITI, N. Freshness assessments of Marroccan sardine (Sardina pilchardus): comparison of overall sensory changes to instrumentally determined volatiles. Journal of Agricultural and Food Chemistry, v. 51, p. 7540-7546, 2003.

TOWNLEY, R. R.; LANIER, T. C. Effect of early evisceration on the keeping quality of Atlantic croaker (Micropogonias furnieri) and grey trout (Cynoscion regalis) as determined by subjective and objective methodology. Jounal of Food Science, v. 3, n. 46, p. 863-867, 1981. 